\title{
SENSITIVITY ANALYSIS OF THE KNAPSACK PROBLEM: TIGHTER LOWER AND UPPER BOUND LIMITS
}

\author{
Tarik BELGACEM ${ }^{\mathbf{1}}$ Mhand HIFI ${ }^{\mathbf{2}}$ \\ ${ }^{I}$ CES - CNRS UMR 8174, Equipe CERMSEM, Université Paris 1 Panthon-Sorbonne \\ 106-112, Boulevard de l'Hôpital, 75647 Paris cedex 13, France \\ belgacem@univ-paris1.fr \\ MIS, Axis: Discrete Optimization and Re-optimization, Université de Picardie Jules Verne \\ 33 rue Saint Leu, 80039 Amiens cedex 01, France \\ mhand.hifi@u-picardie.fr $(\square)$
}

Erratum to: J Syst Sci Syst Eng

DOI: 10.1007/s11518-008-5073-y

The presentation of Table 1 in the original version of this article contained a few typos. The corrected Table 1 is given below.

Table 1 An example

\begin{tabular}{ccccccc}
\hline Item $s$ & $p_{s}$ & $w_{s}$ & $x_{s}$ & $\Delta_{\mathrm{s}}$ & $\rho_{\mathrm{s}}$ & $I_{\mathrm{s}}$ \\
\hline 1 & 37 & 1 & 1 & -34 & $2 / 3$ & -34 \\
2 & 17 & 4 & 1 & -12 & $2 / 3$ & -12 \\
3 & 30 & 14 & 1 & -19 & $2 / 3$ & -19 \\
4 & 21 & 10 & 1 & -12 & $2 / 3$ & -12 \\
5 & 23 & 12 & 1 & -13 & $2 / 3$ & -13 \\
6 & 24 & 27 & 1 & $-\mathbf{6}$ & $5 / 8$ & $-\mathbf{3}$ \\
7 & 24 & 32 & 1 & $-\mathbf{3}$ & $5 / 8$ & $-\mathbf{0}$ \\
8 & 14 & 21 & 0 & 0 & $2 / 3$ & 0 \\
9 & 25 & 40 & 1 & 0 & $2 / 3$ & 0 \\
10 & 19 & 37 & 0 & 2 & $3 / 4$ & 2 \\
11 & 16 & 37 & 0 & 5 & $3 / 4$ & 5 \\
12 & 10 & 25 & 0 & 3 & $3 / 4$ & 3 \\
13 & 8 & 21 & 0 & 3 & $2 / 3$ & 3 \\
14 & 1 & 5 & 0 & 0 & $2 / 3$ & 0 \\
15 & 2 & 21 & 0 & 9 & $2 / 3$ & 9 \\
\hline
\end{tabular}

